\title{
Original \\ Preneoplastic proliferative changes induced by experimental blastocystosis
} Article

\author{
Mazloum M Ahmed, Fayza SM Habib, Ghada A Saad, Heba M EI Naggar
}

Department of Parasitology, Faculty of Medicine, Ain Shams University, Cairo, Egypt

\begin{abstract}
Background: Studying the pathogenic potential of Blastocystis spp. by in vitro and in vivo experimental studies led to suspicions concerning its role in development of cancer colon. Still, this hypothesis remains under investigations. Objective: To investigate the pathology induced in the gut of mice inoculated with Blastocystis spp. isolates derived from patients with and without colorectal carcinoma (CRC).

Subjects and Methods: Seven Blastocystis spp. isolates were derived from patients with CRC, six from non-CRC patients with symptomatic blastocystosis and six from non-CRC asymptomatic Blastocystis spp. carriers. Isolates were used to induce experimental blastocystosis in three groups of three-weeks-old BALB-c mice: GI was inoculated by CRC isolates; GII by symptomatic non-CRC isolates; and GIII by non-CRC asymptomatic isolates. Always, one clinical isolate was used to infect one mouse. Each group contained one negative control mouse inoculated with parasite-free culture medium, kept under the same conditions.

Results: Histopathological examination of sections of intestine of all inoculated mice in the three groups showed positive infection with parasites seen only in the cecum and colon, no parasites were seen in the small intestine. Inflammatory cells infiltrations were detected in mice of the three groups with varying degrees. Vacuolar forms of Blastocystis spp. were seen infiltrating the submucosa in sections from mice in GI (4 mice) and GII (2 mice) but not in GIII. The significant difference in the pathologic changes induced in the intestine of mice in the three groups was observed being more severe with polypoid formation in mice in GI (4 mice) than in GII (1 mouse).

Conclusion: Blastocystis spp. isolates associating CRC differ in their proliferative and invasive pathogenic capabilities than symptomatic isolates. Asymptomatic Blastocystis spp. are non-invasive organisms causing only mild inflammatory response in the large intestine of experimentally infected animals.
\end{abstract}

Keywords: Blastocystis spp.; colorectal carcinoma; histopathological examination; pathogenicity.

Received: 18 April 2019, Accepted: 2 May, 2019.

Corresponding Author: Ghada A Saad; Tel.: 002002 25217977, E-mail: dr_ghadasaad@yahoo.com

Print ISSN: 1687-7942, Online ISSN: 2090-2646, Vol. 12, No. 2, Ausgust, 2019.

\section{INTRODUCTION}

Blastocystis spp. are the most common eukaryotic protist encountered in the gut of both humans and many animals ${ }^{[1]}$. The organism has been diagnosed in both patients with non-specific gastrointestinal symptoms such as nausea, vomiting, diarrhea, abdominal pain, flatulence, and in asymptomatic individuals ${ }^{[2-4]}$. Infection has been associated with a variety of diseases such as irritable bowel syndrome $(\text { IBS })^{[5-9]}$, non-specific colitis, chronic inflammatory bowel disease (IBD) including Crohn's disease and ulcerous colitis ${ }^{[10,11]}$, and with $\mathrm{CRC}^{[12-14]}$. It has been diagnosed in association with non-gastrointestinal disorders such as skin rash and chronic urticaria ${ }^{[15-18]}$, as well as Hashimoto's thyroiditis ${ }^{[19]}$. Because of these discrepancies in associations, and despite the application of recent advances in immunological and molecular methods to Blastocystis spp. research, the pathogenicity of Blastocystis spp.is still controversial and inconclusive ${ }^{[11,20]}$.

The pathogenic potential of Blastocystis spp. has been investigated by in vitro as well as in vivo experimental studies ${ }^{[21]}$. In vitro studies demonstrated the induction of apoptosis in cell lines ${ }^{[2,23]}$ in contrast to the proliferation of human colonic cancer cell line, HCT116, when incubated with Blastocystis spp. organisms ${ }^{[24,25]}$ In vivo studies demonstrated pre-neoplastic changes with the formation of aberrant crypt foci in the colon of Blastocystis spp. experimentally infected rats $^{[6]}$. These studies led to suspicions of Blastocystis spp. as a cause of cancer colon. However, until recently this view remains to be under investigation ${ }^{[20]}$.

The pathological lesions produced in animals by Blastocystis spp. isolates derived from asymptomatic and symptomatic infected humans with gastrointestinal manifestations ${ }^{[27-30]}$, and from patients with $\operatorname{IBS}^{[7,31,32]}$ have been studied and compared. The present study aims to investigate the pathology induced in the gut of mice inoculated with Blastocystis spp. isolates derived from patients with and without CRC to discover the possible oncogenic potential of the parasite.

\section{SUBJECTS AND METHODS}

This descriptive experimental study was conducted at the Parasitological Research and Diagnostic Laboratory 
Unit of Parasitology Department, Faculty of Medicine, Ain-Shams University during the interval from September, 2017 to February, 2018.

Subjects: Individuals infected with Blastocystis spp. identified as the only possible parasite in their stools were included in the present work. They were selected from attendants of the outpatient clinics of El Demerdash Hospitals and from persons referred to the Parasitology Research and Diagnostic Laboratory Unit of Medical Parasitology Department, Faculty of Medicine, Ain Shams University. Participants in the study included patients with early diagnosed CRC who had not received any chemotherapeutic drugs (GI); symptomatic patients suffering symptoms related to gastrointestinal disorders, such as diarrhea, abdominal pain and distension (GII); and asymptomatic carriers (GIII). Each participant was subjected to the following: (i) questionnaire with a thorough medical history covering the personal data, the presence of GIT symptoms related to Blastocystis spp. infection (diarrhea, abdominal pain, constipation, flatulence), current health status with special emphasis on diagnosis of colorectal carcinoma, previous parasitic infections, and drug intake; (ii) complete clinical examination including general and abdominal examination to exclude other conditions.

Stool samples: All participants were asked to provide three stool samples in clean, wide, disposable stool containers. Each sample was examined by direct smear examination, iodine, and trichrome staining, and by formalin-ethyl acetate concentration technique ${ }^{[33]}$, to diagnose Blastocystis infection and exclude other parasitic causes of GIT symptoms. Modified Ziehl-Neelsen acid-fast stain was used to exclude Cryptosporidium, Cyclospora, Isospora, and Microsporidium-infected patients ${ }^{[33]}$. In vitro cultivation was performed for each stool sample by inoculation of fresh stool in Locke's egg serum medium ${ }^{[34]}$. The cultures were incubated at $37^{\circ} \mathrm{C}$ and examination of 3-4 days-old cultures was done under $\times 10$ and $\times 40$ magnifications. On observing the typical vacuolar or granular forms of Blastocystis spp. organisms, they were sub-cultured in a new medium for several subcultures supplemented with antibiotics to minimize bacterial contamination before being used for animal inoculation.

Blastocystis isolates: Nineteen Blastocystis isolates were employed in the present study. These included isolates derived from patients with CRC $(\mathrm{n}=7)$; from symptomatic blastocystosis patients with gastrointestinal symptoms $(n=6)$; and from asymptomatic Blastocystis spp. carriers $(\mathrm{n}=6)$.

Experimental animals: Three-weeks-old male BALB-c mice used in the present study, were obtained from Ain-Shams University Research Institute Animal House. Stool samples of mice were subjected to direct parasitological examination to confirm the absence of enteric parasites. All samples were cultured to exclude Blastocystis infection. The animals were separately maintained in polycarbonate cages with paper bedding, at $25^{\circ} \mathrm{C}$, in the animal house, with a relative humidity of $40-60 \%$ and under a 12 -hour light/dark cycle. They were fed a normal diet of commercial pellets and given potable water ad libitum. The cages and paper bedding were changed at weekly intervals.

Experimental infections and design: Blastocystis spp. organisms in 3-4 days-old cultures were harvested and purified by Ficoll-Hypaque density gradient centrifugation ${ }^{[35]}$ to remove bacterial load in each isolate, and to exclude bacterial infection as a possible cause of histopathological changes occurring in experimental studies. After counting the number of cells using a hemocytometer, number of cultured forms was adjusted to $1 \times 10^{5} / \mathrm{ml}$. Cells were immediately intra-gastrically inoculated orally into the animals by 16-G ball-tipped feeding needle attached to one $\mathrm{ml}$ syringe ${ }^{[36]}$.

Mice were divided into three groups: GI, 7 mice inoculated by organisms of isolates derived from CRC patients; GII, 6 mice inoculated by organisms of isolates derived from symptomatic non-CRC patients; and GIII, 6 mice inoculated by organisms of isolates derived from asymptomatic non-CRC Blastocystis carriers (Table 1). In GI and GII one mouse was inoculated for each clinical isolate. Each group of mice included one additional mouse inoculated with one $\mathrm{ml}$ parasite-free culture medium, kept under the same conditions, and considered as negative control for each group. These were housed separately to avoid feco-oral transmission of infection. Meanwhile, only one mouse was housed per cage to facilitate collection of stool samples and diagnosis of infection. Stool samples from all mice were screened for the presence of infection daily for one week post infection (PI) by wet mount examination and culture in Locke' egg slant serum medium ${ }^{[34]}$. The culture was considered negative if the organism was Time absent until the $7^{\text {th }}$ day. Two weeks PI, all mice were anesthetized by ether and euthanized by disc dislocation. Large intestine (colon and cecum) was assessed by naked eye, removed, preserved in $10 \%$ formalin, and processed in paraffin blocks.

Table 1. Date of diagnosis of infection in experimentally infected mice.

\begin{tabular}{lccc}
\hline \hline \multirow{2}{*}{$\begin{array}{l}\text { Group/ } \\
\text { No. of mice }\end{array}$} & \multicolumn{3}{c}{$\begin{array}{c}\text { Date of diagnosis of experimental } \\
\text { blastocystosis in mice }\end{array}$} \\
\cline { 2 - 4 } & D 4 PI & D 5 PI & D 6 PI \\
\hline G I (7) & $\mathbf{4}$ & $\mathbf{3}$ & $\mathbf{0}$ \\
G II (6) & $\mathbf{6}$ & $\mathbf{0}$ & $\mathbf{0}$ \\
G III (6) & $\mathbf{0}$ & $\mathbf{3}$ & $\mathbf{3}$ \\
\hline \hline Group I: mice infected with isolates from CRC patients; Group \\
II: mice infected with isolates from non-CRC symptomatic \\
patients; Group III: mice infected with isolates from non-CRC \\
asymptomatic individuals. PI: post infection. \\
\hline
\end{tabular}


Histopathology: Paraffin blocks of tissue samples were sectioned, stained with hematoxylin-eosin and examined microscopically using $40 \mathrm{x}$ and $100 \mathrm{x}$ objectives. Grading of the degree of inflammatory cell infiltration and tissue destruction was assessed as described by Riley et al. ${ }^{(37)}$.

Statistical analysis: Results are expressed as number and percent. Statistical analyses were carried out using SPSS version 20. Pearson Chi-square (2?) test was used to compare results. The significance level was considered at probability $P<0.05$. Data are presented by descriptive tables and appropriate figures.

Ethical considerations: All participants were acquainted with the study details and agreed to participate in it. The procedures employed in the present experiments complied with the current ethics guidelines set out by Ain Shams University. General principles for care and use of animals in experiments for scientific purposes were followed as recommended by the National Advisory Committee for Laboratory Animal Research. The research protocol was approved by the Ethics Committee, Faculty of Medicine, AinShams University.

\section{RESULTS}

All isolates included in the study were infectious to mice with positive diagnosis starting from $4^{\text {th }}$ to $6^{\text {th }}$ day PI with no statistically significant differences. The infection was diagnosed on the $4^{\text {th }}$ day PI in $4 / 7$ mice included in GI inoculated with isolates from CRC patients, and in all mice in GII inoculated with isolates from the non-CRC symptomatic patients. Infection was diagnosed on the $5^{\text {th }}$ day PI ( 3 mice) from GI, and on the $5^{\text {th }}$ and $6^{\text {th }}$ days PI ( 3 mice respectively) inoculated with isolates from the non-CRC asymptomatic GIII (Table 1). No mortality or lethargy was observed in the animals throughout the study.

Naked eye appearance of intestine: Gross morphology of the large intestine and cecum of all isolates of GIII mice, inoculated with asymptomatic isolates, showed no abnormalities compared to features seen in the non-infected control animal. On the other hand, some redness and bloated cecum were observed in four mice of GI (CRC group) and two mice in GII (non-CRC symptomatic group) compared to controls.

Histopathological examination: Histopathological examination of the intestine of mice of the three groups, revealed Blastocystis vacuolar forms in the lumen of the large intestine, mainly in the cecum with no organisms detected in the small intestine. Blastocystis spp. parasites were detected at the edge of the mucosa, trapped in the epithelial lining near the surface (Figures 1 and 2). Different degrees of pathological changes were detected among mice infected by isolates from CRC(GI), non-CRC symptomatic- (GII) and asymptomatic(GIII) patients (Table 2). Intense and severe degree of pathological changes were seen in sections of the intestine of all mice inoculated by CRC-isolates (GI) with severe and mixed inflammatory cells infiltration throughout the lamina propria namely lymphocytes, eosinophils, and sporadic polymorphs with the appearance of lymphocytic aggregation throughout the mucosal layer. The inflammatory cells infiltration was moderate to severe in sections of the intestine of mice of GII and mild to moderate in case of mice of GIII (Table 2; Figures 1, 2, and 3).

Collections of Blastocystis vacuolar forms were observed in the submucosa and lamina propria in sections of the colon and cecum of 4 mice in GI. Precancerous proliferative lesions in the form of polypoid projections with fibrovascular core covered with hyperplastic mucosa of the colon were noticed in some areas of the mucosa of these 4 mice, (Figure 1 a-c). Only sporadic vacuolar forms were seen invading the submucosa of 2 mice in GII (Figure 2). One of these two mice showed one or two polypoid projections like those noticed in mice of GI (Figure 1d). No Blastocystis organisms were seen invading the submucosa in sections of the intestine of mice of GIII. Also, no proliferative changes were seen in the mucosa of mice of GIII (Figure 3). There was no invasion detected in the muscularis mucosa by any of the Blastocystis stages in all groups studied. The mucosal epithelium showed no ulceration or dysplasia. Statistically significant differences existed on comparing the pathological lesions produced in mice of the three groups in relation to the clinical source of isolates $(P<0.049)$.

Table 2. Histopathologic findings in mice inoculated with Blastocystis isolates derived from CRC patients (GI), non-CRC symptomatic patients (GII) and non-CRC asymptomatic carriers (GIII).

\begin{tabular}{lcccc}
\hline \hline \multirow{2}{*}{ Group/Histopathological findings } & GI & GII & GIII & \multirow{2}{*}{$P$ value } \\
\cline { 2 - 4 } & No. $=\mathbf{7}$ & No. = 6 & No. = 6 & - \\
\hline $\begin{array}{l}\text { Degree of inflammation and inflammatory cells infiltration } \\
\text { in mucosa }\end{array}$ & Severe & $\begin{array}{c}\text { Moderate } \\
\text { to severe }\end{array}$ & $\begin{array}{c}\text { Mild to } \\
\text { moderate }\end{array}$ \\
$\begin{array}{l}\text { Number (\%) of mice with Blastocystis vacuolar forms } \\
\text { mucosal invasion/total number of mice in the group }\end{array}$ & $4 / 7$ & $2 / 6$ & $0 / 6$ & - \\
Number (\%) of mice with induced proliferative lesions & $(57.14 \%)$ & $(33.33 \%)$ & $(0 \%)$ & \multirow{2}{*}{$\mathbf{0 . 0 4 9 *}$} \\
and polyp formation/ total number of mice in the group & $(57.14 \%)$ & $(16.6 \%)$ & $(0 \%)$ & $0 / 6$ \\
\hline
\end{tabular}

*Significant $P$ value $<0.05$ 

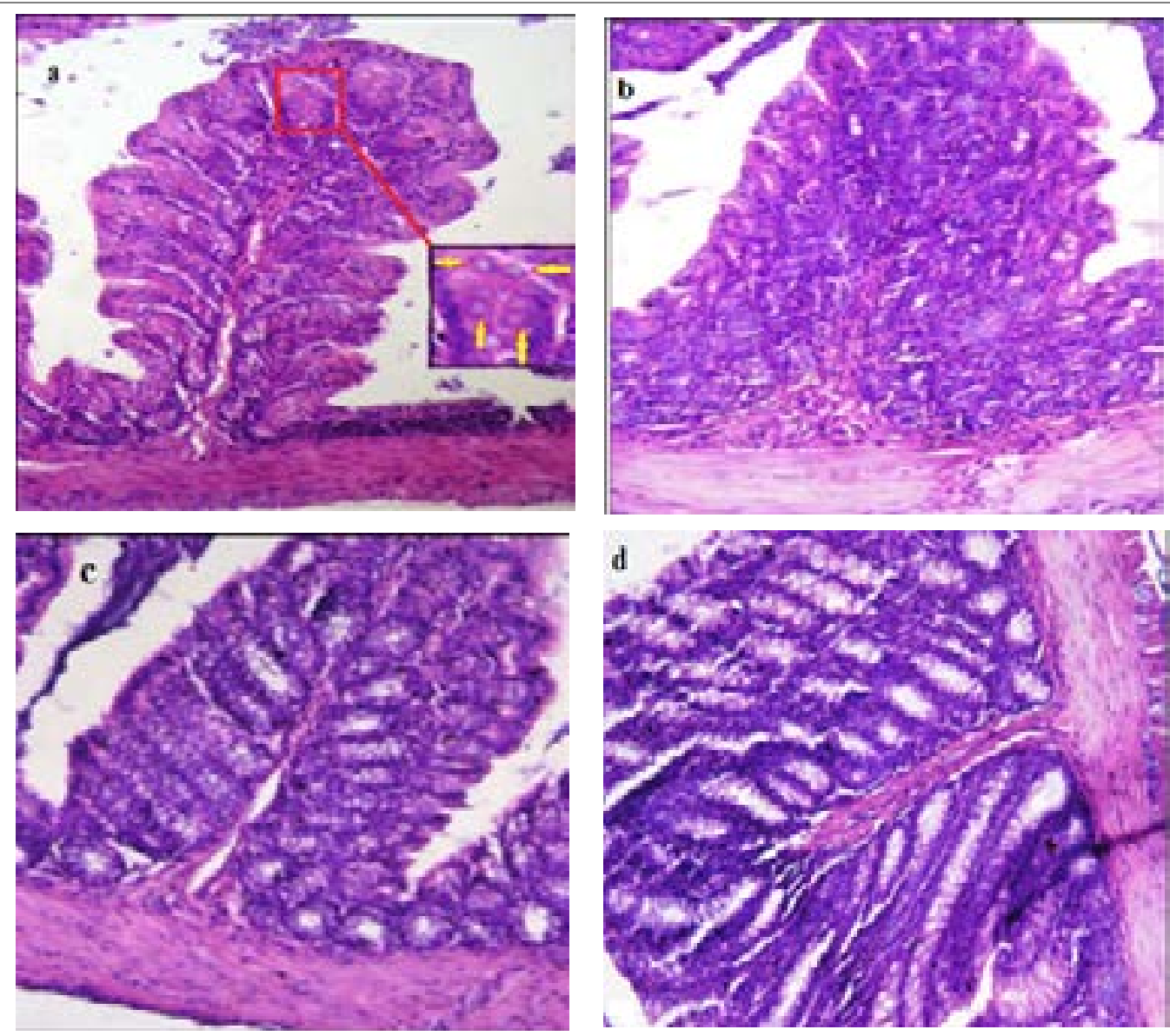

Fig. 1. Tissue sections from large intestine of mice in GI (a, b and c) infected with CRC-Blastocystis spp., and a mouse in GII (d) infected with non-CRC symptomatic isolate showing polypoid projections with fibrovascular cores. $\mathrm{H} \& \mathrm{E}, \times 400$. The box in (a) shows magnified vacuolar forms of Blastocystis with the peripheral nuclei and the central vacuole.

Fig. 2. Tissue section from large intestine of a mouse in GII infected with an isolate of non-CRC-symptomatic Blastocystis spp. The lamina propria is packed with mixed inflammatory cells (arrows) in the form of eosinophils, lymphocytes, plasma cells, and vacuolar forms of Blastocystis infiltrating the submucosa (in circles) (H\&E 400x).

Fig. 3. Section of the large intestine of a mouse infected with an isolate from GIII (non-CRC asymptomatic) showing the lamina propria with mild mixed inflammatory cells (black arrows) (H\&E, $400 \mathrm{x}$ ).
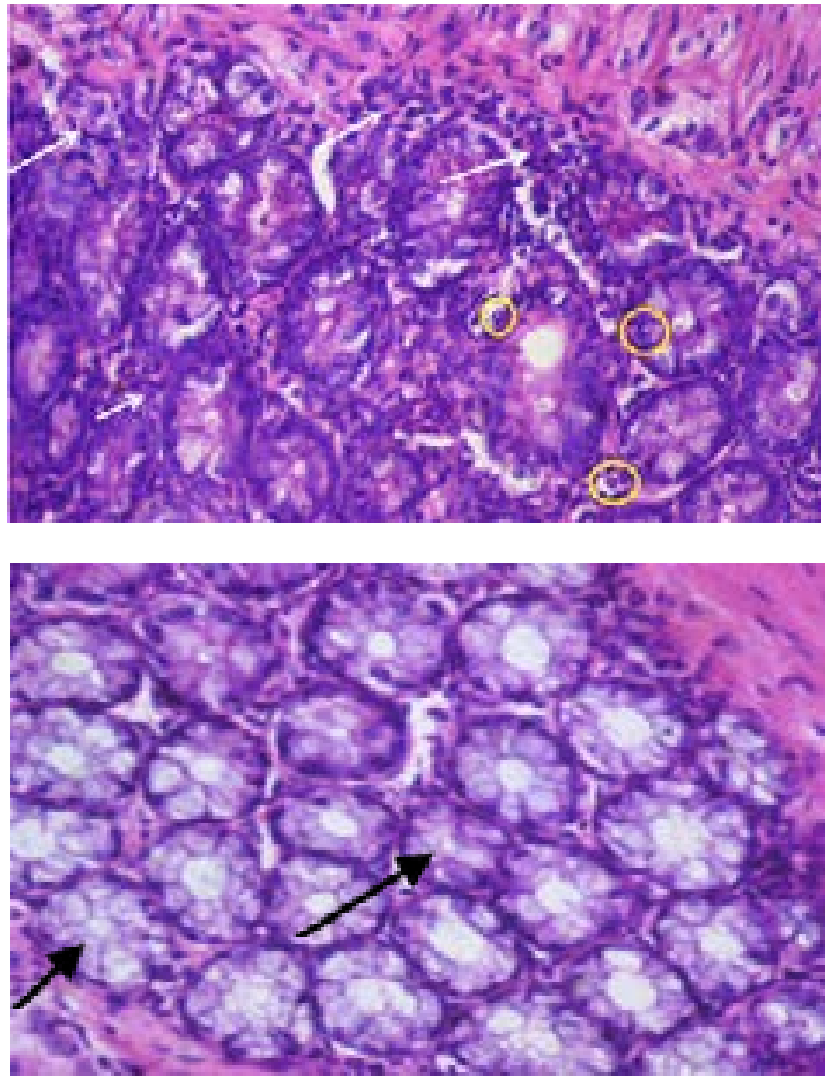


\section{DISCUSSION}

In the present study, experimental blastocystosis was induced in mice to compare the pathogenic effects of Blastocystis spp. isolates derived from CRC patients with those produced by isolates derived from non-CRC and from other asymptomatic individuals. Blastocystis spp. isolates from CRC patients included in the study were obtained from patients diagnosed with colorectal carcinoma before beginning any chemotherapeutic therapy to exclude possible effects of the drugs on the isolates. Also, persons infected with other parasitic infections were excluded to ensure that the causative organism of symptoms in symptomatic patients was Blastocystis.

Previously experimental blastocystosis was induced in many animal models including pigs, guinea pigs, mice, chickens and rats with conflicting results on the pathogenic potential of Blastocystis ${ }^{[38]}$. Healthy pigs ${ }^{[20]}$ and rats ${ }^{[39]}$ are recommended for use as animal models for the pathogenicity of Blastocystis spp. However it was recommended to screen these animals for current infection before starting experimentation as both animals are natural hosts for Blastocystis spp. with absence of signs of damage to their intestines ${ }^{[38,40,41]}$. Although chickens could be inoculated with Blastocystis spp., authors observed that not all human isolates of Blastocystis spp. can infect chickens and rats ${ }^{[42]}$. Mice are more suitable for immunology studies than rats as the possibility of rats exhibiting previous immunity to Blastocystis spp. can lead to errors ${ }^{[21]}$. It is important to notice that older mice are refractory to Blastocystis spp. requiring induction of mild colitis using 2\% DSS (Dextran Sulfate Sodium) prior to infection ${ }^{[39]}$. Thus, caution should be observed when choosing a suitable animal model to study blastocystosis. In our animal experimental study, and as previously reported ${ }^{[28,29,43,44]}$, 3 weeks-old mice were used successfully to produce blastocystosis. All Blastocystis spp. isolates were infectious to animals used.

In the present work, experimental blastocystosis was successfully induced in all BALB-c mice by intragastric inoculation with $1.0 \times 10^{5}$ Blastocystis organisms in $100 \mu \mathrm{l}$ saline. In the work of El Wakil and Hewedy[28], similar inoculum doses produced infection in only $40 \%$ of the animals while in the work of Pavanelli et al. ${ }^{[44]}$, a smaller inoculum of $1.0 \times 10^{2}$ produced infection in all animals. These variations may be due to differences in infectivity of Blastocystis spp. in different studies. Positive stools examinations of mice began from 4 to 6 days PI in the three groups. Earlier diagnosis of infection of 2 to 5 days $^{[28,44]}$ in mice, and 3 to 4 days $^{[6]}$ in rats were reported depending on the inoculum size.

As regards the naked eye appearance of mice intestine, cecum and colon of mice in GI inoculated with CRC isolates and mice in GII inoculated with nonCRC symptomatic isolates, showed some redness and bloating in contrast to those inoculated by asymptomatic isolates that showed normal gross morphology. This was similar to the results observed by Abaza et al. ${ }^{[6]}$ who noticed redness and bloating in cecum and colon of rats infected by symptomatic isolates, but not in those inoculated by asymptomatic isolates and isolates derived from IBS patients, suggesting differences in pathogenicity of human' isolates derived from persons with different clinical presentations.

The absence of parasites in the small intestine in all infected mice is consistent with previous reports ${ }^{[6,28,29,31,43]}$ that detected Blastocystis spp. organisms only in the cecum and colon. Only in immunecompromised mice, were Blastocystis organisms found in the whole GIT ${ }^{[13]}$.

Although the amoeboid form is the proposed pathogenic form of Blastocystis spp. ${ }^{[46-48]}$, yet in studies describing the histopathology of experimental blastocystosis, only the vacuolar forms were reported to invade the wall of the intestine $\mathrm{e}^{[6,20,28,31,32,45,49,50]}$, Similarly, in the present work in sections of the large intestine of mice in GI (4/7 mice) and GII (2/6 mice), only the lamina propria appeared to be invaded by the vacuolar forms. Invasion of the lamina propria, submucosa and reaching up to the muscular layer of the intestine by vacuolar forms was seen only with high infective doses ${ }^{[28,44]}$, demonstrating the impact of the higher dose of inoculum. Vacuolar forms of Blastocystis spp. have been noticed in vitro studies to produce disruption of intestinal epithelial monolayer and the occluding tight junctions (ZO-1), as well as increased membrane permeability ${ }^{[21-53]}$. Proteases excreted both in and on the cell surface of Blastocystis spp. are accused of being the virulence factor and their activity may determine the pathogenicity of an isolate. Cysteine proteases concentrated in the central vacuole of the vacuolar forms ${ }^{[54]}$ are accused of causing apoptosis and membrane permeability of host cells ${ }^{[51]}$. Therefore as observed, further investigation is needed to ascertain the role of the amoeboid and vacuolar forms in pathogenicity ${ }^{[20]}$.

Different degrees of pathological changes were reported among mice and rats experimentally infected by symptomatic human isolates compared with asymptomatic isolates ${ }^{[6,31,45,49,50]}$. A mild degree of inflammation with few inflammatory cells infiltration and aggregates of lymphocytes was previously reported in rats, with the parasite seen at the luminal aspect of the colon when the animals were inoculated by asymptomatic isolates ${ }^{[6,31]}$. Similarly, edematous lamina propria with mild inflammatory cellular infiltration especially neutrophils, eosinophils and lymphocytes were reported in experimentally infected mice ${ }^{[29]}$. Researchers reported that Blastocystis spp. organisms were seen, only, on the luminal border of the large intestine ${ }^{[6,31]}$. A similar picture with mild inflammatory reaction was noticed in mice inoculated by isolates 
derived from asymptomatic carriers included in our study. On the other hand, isolates from symptomatic patients have been observed, in many studies, to cause more severe and intense pathological changes with mucosal sloughing, intense inflammatory cells infiltration, and parasite infiltration of lamina propria in mice ${ }^{[28,30,44,49]}$ and rats ${ }^{[6,27,31,55]}$. In addition, Hussein et $a l^{[31]}$ and Abaza et al. ${ }^{[6]}$ reported the induction of a more severe degree of pathological change with polypoid projections in colonic mucosa of rats infected by symptomatic isolates, that the authors referred to as precancerous polyps. In the present study, comparable results were recorded as the active colitis produced in mice ranged from severe in mice in GI, to moderate in mice in GII, to mild in mice in GIII, with intense inflammatory cells infiltration and formation of lymphocytic aggregation in mice in GI and GII. Polypoid projections in colonic mucosa were also significantly noticed in our present study in $57.14 \%$ of mice in GI $(P=0.049)$, and insignificantly in $16.66 \%$ of mice in $\mathrm{GII}$, and were not found to occur in mice inoculated by asymptomatic isolates in GIII).

Recently, studies demonstrating phenotypic differentiating characters between Blastocystis spp. isolates derived from persons diagnosed with or without CRC have been published. Differences included different in vitro growth pattern and metronidazole susceptibility ${ }^{[56]}$, and in the surface ultrastructure, protein profiles and zymography ${ }^{[57]}$. Our study confirms the presence of differences in the pathogenic potential of different Blastocystis spp. isolates with possible oncogenic potential in some of them.

In conclusion, Blastocystis spp. isolates associating colorectal carcinoma differ in their proliferative and invasive pathogenic capabilities than symptomatic isolates. Moreover, asymptomatic Blastocystis spp. are non-invasive organisms causing only mild inflammatory response in the large intestine of experimentally infected animals.

Authors Contribution: Ahmed MM shared in designing the plan of work and revising the manuscript; Habib FSM conceived and designed the plan of work, analyzed the data, wrote and revised the manuscript; Saad GA shared in performing the culture, experimental infections and, histopathological analysis; ElNaggar HM performed the culture, shared in experimental infection and histopathological analysis.

Conflict of Interest: Authors declare that there is no conflict of interest.

\section{REFERENCES}

1. Tan KS. New insights on classification, identification, and clinical relevance of Blastocystis spp. Clin Microbiol Rev 2008; 21: 639-665.
2. Taşova Y, Sahin B, Koltaş S, Paydaş S. Clinical significance and frequency of Blastocystis hominis in Turkish patients with hematological malignancy. Acta Med Okayama 2000; 54 (3): 133-136.

3. Tan KSW, Mirza H, Teo JDW, Wu B, Macary PA. Current views on the clinical relevance of Blastocystis spp. Curr Infect Dis Rep 2010; 12: 2835.

4. Scanlan PD, Stensvold CR, Rajilić-Stojanović M, Heilig HG, De Vos WM, O'Toole PW, et al. The microbial eukaryote Blastocystis is a prevalent and diverse member of the healthy human gut microbiota. FEMS Microbiol Ecol 2014; 90: 326-330.

5. Yakoob J, Jafri W, Jafri, N, Islam M, Beg MA. In vitro susceptibility of Blastocystis hominis isolated from patients with irritable bowel syndrome. Br J Biomed Sci 2004; 61:75-77.

6. Abaza SM, Rayan HZ, Soliman RH, Nemr NA, Mokhtar AB. Subtype analysis of Blastocystis spp. isolates from symptomatic and asymptomatic patients in Suez Canal University Hospitals, Ismailia, Egypt. PUJ 2014; 7: 56-67.

7. Nourrisson C, Scanzi J, Pereira B, NkoudMongo C, Wawrzyniak I, Cian A, et al. Blastocystis is associated with decrease of fecal microbiota protective bacteria: comparative analysis between patients with irritable bowel syndrome and control subjects. PLoS ONE 2014; 9 (11): e111868.

8. Azizian M, Basati G, Abangah G, Mahmoudi MR, Mirzaei A. Contribution of Blastocystis hominis subtypes and associated inflammatory factors in development of irritable bowel syndrome. Parasitol Res 2016; 115 (5): 2003-2009.

9. Lepczyńska M, Dzika E, Kubiak K, KorycińskaJ. The role of Blastocystis spp. as an etiology of irritable bowel syndrome. Pol Ann Med 2016; 23 (1): 57-60.

10. Basak S, Rajurkar MN, Mallick SK. Detection of Blastocystis hominis: A controversial human pathogen. Parasitol Res 2014; 113(1): 261-265.

11. Tasić N, Milenković T, Bujić V, Zdravković D, Tasić A. Blastocystis hominis: a mysterious and commonly disregarded parasite. Med and Bio 2016; 18 (2):3947.

12. Kumarasamy V, Kuppusamy UR, Samudi C, Kumar S. Blastocystis spp. subtype 3 triggers higher proliferation of human colorectal cancer cells, HCT116. Parasitol Res 2013; 112: 3551-3555

13. Ahmed MA, Mohamed AM, Ahmed SAM, Zaglool DA, Al-Semany SA. Predominance of Blastocystis hominis subtype I among colorectal cancer patients in Makkah, Saudi Arabia. J Bacteriol Parasitol 2016; 7:5(Suppl).

14. Mohamed AM, Ahmed MA, Ahmed SA, Al-Semany SA, Alghamdi SS Zaglool DA. Predominance and association risk of Blastocystis hominis subtype I in colorectal cancer: a case-control study. Infect Agents Cancer 2017; 12: 21.

15. Valsecchi R, Leghissa P and Greco V. Cutaneous lesions in Blastocystis hominis infection. Acta DermVenereol 2004; 84: 322-323. 
16. Vogelberg C, Stensvold CR, Monecke S, Ditzen A, Stopsack K, Heinrich-Gräfe U, et al. Blastocystis spp. subtype 2 detection during recurrence of gastrointestinal and urticarial symptoms. Parasitol Int 2010; 59 (3): 469-471.

17. Bálint A, Dóczi I, Bereczki L, Gyulai R, Szűcs M, Farkas $\mathrm{K}$, et al. Do not forget the stool examination, cutaneous and gastrointestinal manifestations of Blastocystis sp. infection. Parasitol Res 2014; 113 (4): 1585-1590.

18. Casero RD, Mongi F, Sánchez A, Ramírez JD. Blastocystis and urticaria: Examination of subtypes and morphotypes in an unusual clinical manifestation. Acta Trop 2015;148: 156-161.

19. Rajič B, Arapović J, Raguž K, Bošković M, Babić SM, Maslać S. Eradication of Blastocystis hominis prevents the development of symptomatic Hashimoto's thyroiditis: a case report. J Infect Dev Ctries 2015: 9 (7): 788-791.

20. Adao DEV, Rivera WL. Recent advances in Blastocystis spp. research. Philip Sci Lett 2018; 11(01): 39-60.

21. Ajjampur SS, Tan KS. Pathogenic mechanisms in Blastocystis spp. - interpreting results from in vitro and in vivo studies. Parasitol Int 2016; 65 (6 Pt B): 772-779.

22. Puthia MK, Sio SW, Lu J, Tan KSW. Blastocystis ratti induces contact-independent apoptosis, F-actin rearrangement, and barrier function disruption in IEC-6 cells. Infect Immun 2006; 74 (7): 4114-4123.

23. Zhaona $\mathrm{Wu}$, Haris $\mathrm{M}$, Joshua $\mathrm{D}$, Teo W, Kevin S, Tan W. Strain-dependent induction of human enterocyte apoptosis by Blastocystis disrupts epithelial barrier and Z0-1 organization in a Caspase 3- and 9-dependent manner. BioMed Res Internat 2014;209163

24. Chandramathi S, Suresh K, Kuppusamy UR. Solubilized antigen of Blastocystis hominis facilitates the growth of human colorectal cancer cells, HCT116. Parasitol Res 2010; 106 (4): 941-945.

25. Chan KH, Chandramathi S, Suresh K, Chua KH, Kuppusamy UR. Effects of symptomatic and asymptomatic isolates of Blastocystis hominis on colorectal cancer cell line, HCT116. Parasitol Res 2012; 110: 2475-2480.

26. Kumarasamy V, Kuppusamy UR, Jayalakshmi P, Samudi C, Ragavan ND, Kumar S. Exacerbation of colon carcinogenesis by Blastocystis spp. PLoS One 2017; 12(8): e0183097.

27. Iguchi $A$, Yoshikawa $H$, Yamada $M$, Kimata I, Arizono N. Expression of interferon gamma and proinflammatory cytokines in the cecal mucosa of rats experimentally infected with Blastocystis sp. strain RN94-9. Parasitol Res 2009; 105 (1): 135140.

28. El-Wakil HS,Hewedi IH. Pathogenic potential of Blastocystis hominis in laboratory mice. Parasitol Res 2010; 107: 685-689.

29. El-Gebaly, NS, Zaki MM. Ultrastructural intestinal pathology induced by human Blastocystis in experimentally infected mice. PUJ 2012; 5(2): 127134.

30. Abdel-Hafeez EH, Ahmad AK, Abdelgelil NH, Abdellatif MZ, Kamal AM, Hassanin KM, et al. Immunopathological assessments of human Blastocystis spp. in experimentally infected immune-competent and immune-suppressed mice. Parasitol Res 2016; 115(5): 2061-2071.

31. Hussein EM, Hussein AM, Eida MM, Atwa M. Pathophysiological variability of different genotypes of human Blastocystis hominis Egyptian isolates in experimentally infected rats. Parasitol Res 2008; 102: 853-860.

32. Abu El-Fetouh NI, Abdel Megeed ES, Attia RA, ElDosoky I, Azab MS. Genotyping of Blastocystis hominis symptomatic isolates and kinetics of associated local CD3 and CD20 cell infiltrate. PUJ 2015; 8: 115-122.

33. Garcia LS. Diagnostic Medical Parasitology. $6^{\text {th }}$ edition,.2015 Press, Washington.

34. Saksirisampant W, Nuchprayoon S, Pradniwat P, Lamchuan D. Boeck and Drbohlav Locke egg serum medium for detection of Blastocystis hominis. Chula Med J 2010; 54 (6): 527-536.

35. Lanuza MD, Carbajal JA, VillarJ, Borrás R. Description of an improved method for Blastocystis hominis culture and axenization. Parasitol Res 1997; 83: 60-63.

36. Yoshikawa H, Yoshida K, Nakajima A, Yamanri K, Iwatani S, Kimata M. Feco-oral transmission of the cyst form of Blastocystis hominis in rats. Parasitol Res 2004; 94:361-366

37. Riley SA, Mani V, Goodman MJ, Herd ME, Dutt S, Turnberg LA. Comparison of delayed release 5-aminosalicylic acid (mesalazine) and sulphasalazine in the treatment of mild to moderate ulcerative colitis relapse. Gut 1988;29:669-674.

38. Wang W, Bielefeldt-Ohmann H, Traub RJ, Cuttell $\mathrm{L}$, Owen H. Location and pathogenic potential of Blastocystis in the porcine intestine. PLoS ONE 2014a 9 (8): e103962.

39. Ajjampur SSR, Png CW, Chia WN, Zhang, Y, Tan KSW. Ex-vivo and in vivo mice models to study Blastocystis spp. adhesion, colonization, and pathology: closer to proving Koch's postulates. PLoS. ONE 2016; 11(8).

40. Fayer R, Elsasser T, R, Solano G, Urban Jr J, Santin M. Blastocystis tropism in the pig intestine. Parasitol Res 2014; 113 (4): 1465-1472.

41. Wang W, Owen H, Traub RJ, Cuttell L, Inpankaew $\mathrm{T}$, Bielefeldt-Ohmann H. Molecular epidemiology of Blastocystis in pigs and their in-contact humans in Southeast Queensland, Australia, and Cambodia. Vet Parasitol 2014b; 203: 264-269.

42. Iguchi A, Ebisu A, Nagata S, Saitou Y, Yoshikawa H, Iwatani $\mathrm{S}$, et al. Infectivity of different genotypes of human Blastocystis hominis isolates in chickens and rats. Parasitol Int 2007; 56 (2): 107-112.

43. Hegazy MM, Maklouf LM, El Hamshary EM, Dawoud HA, Eida AM. Protein profile and morphometry of 
cultured human Blastocystis hominis from children with gastroenteritis and healthy ones. J Egypt Soc. Parasitol 2008; 38(2): 453-464.

44. Pavanelli MF, Kaneshima EN, Uda CF, Colli CM, Ana L, Falavigna-guilherme AL, et al. Pathogenicity of Blastocystis spp. to the gastrointestinal tract of mice: relationship between inoculum size and period of infection. Rev Inst Med Trop Sao Paulo 2015; 57(6): 467-472.

45. Yao FR, Qiao JY, Zhao Y, Zhang X, Yang JH, Li XQ. Experimental infection of mice with Blastocystis hominis, Zhongguo Ji Sheng ChongXue Yu Ji Sheng Chong Bing Za Zhi 2005; 23:444-448.

46. Tan T, Suresh K. Predominance of amoeboid forms of Blastocystis hominis in isolates from symptomatic patients. Parasitol Res 2006; 98 (3): 189-193.

47. Popruk S, Pintong A, Radomyos P. Diversity of Blastocystis subtypes in humans. J Trop Med Parasitol 2013; 36: 88-97.

48. RajamanikamA, Govind SK. Amoebic forms of Blastocystis spp.: evidence for a pathogenic role. Parasit Vectors 2013; 6: 295-303

49. Moe KT, Singh M, Howe J, Ho LC, Tan SW, Chen XQ, et al. Experimental Blastocystis hominis infection in laboratory mice. Parasitol Res 1997; 83: 319-325.

50. Abou El-Naga IF, Negm A. Morphology, histochemistry and infectivity of Blastocystis hominis cyst. J Egypt Soc Parasitol 2001; 31: 627635.

51. Mirza H, Wu Z, Teo JD, Tan KS. Statin pleiotropy prevents rho kinase-mediated intestinal epithelial barrier compromise induced by Blastocystis cysteine proteases. Cell Microbiol 2012; 14: 1474 1484.

52. Wu, Z, Mirza H, Tan KS. Intra-subtype variation in entero-adhesion accounts for differences in epithelial barrier disruption and is associated with metronidazole resistance in Blastocystis subtype-7. PLoSNegl Trop Dis 2014a 8: e2885.

53. Wu Z, Mirza H, Teo JD, Tan KS. Strain-dependent induction of human enterocyte apoptosis by Blastocystis disrupts epithelial barrier and ZO-1 organization in a caspase 3- and 9-dependent manner. Biomed Res Int 2014; 209163.

54. Puthia MK, Lu J, Tan KSW. Blastocystis ratti contains cysteine proteases that mediate interleukin-8 response from human intestinal epithelial cells in an NF-kB-dependent manner. Eukaryot Cell 2008; 7: 435-443.

55. Chandramathi S, Suresh K, Sivanandam S, Kuppusamy UR. Stress exacerbates infectivity and pathogenicity of Blastocystis hominis: in vitro and in vivo evidences. PLoS One 2014; 9: e94567.

56. Habib FSM, Abdel-Fattah NS, Saad GA, El Naggar HM. Growth kinetics and metronidazole sensitivity of Blastocystis spp. isolated from colorectal carcinoma (CRC) and non-CRC patients. PUJ 2018; 11(3): 175-180.

57. Ahmed MA, Habib FSM, Saad GA, El Naggar HM. Surface ultrastructure, protein profile and zymography of Blastocystis species isolated from patients with colorectal carcinoma. J Parasit Dis 2019; doi.org/10.1007/s12639-019-01092-9. 10 pages. 